\title{
DIFICULDADES ENFRENTADAS PELOS PROFESSORES PARA REALIZAR ATIVIDADES DE EDUCAÇÃO AMBIENTAL EM ESPAÇOS NÃO FORMAIS
}

\author{
Diana Antonia Louzada XAVIER ${ }^{1}$ \\ Secretaria Municipal de Educação do Moju/SEMED \\ antoniadiana1@hotmail.com \\ Priscyla Cristinny Santiago da $\mathbf{L U Z}^{2}$ \\ Universidade do Estado do Pará/UEPA \\ biocylla@yahoo.com.bruz
}

Resumo: Este trabalho tem como objetivo identificar as principais dificuldades apontadas na realização de atividades em espaços não formais acerca da temática ambiental, pelos docentes do ensino fundamental da cidade de Moju. A coleta de dados ocorreu com visitas e entrevistas realizadas com coordenadores dos espaços não formais: Parque Radini presente no município de Abaetetuba-PA e Unidade de Triagem e Reciclagem presentes no município de Moju-PA. Também foram realizadas entrevistas semiestruturadas com professores que atuam no ensino fundamental de $5^{a}$ a $8^{a}$ série das Escolas Antônio de Oliveira Gordo, Oton Gomes de Lima, Tia Erica e a Lauro Sodré presentes no município de Moju-PA. Os dados foram organizados, discutidos e analisados segundo a Análise do Discurso, de Orlandi (2001). De acordo com os resultados, identificaram-se como principais dificuldades apontadas pelos docentes a falta de tempo, a falta de

1 Professora da Secretaria Municipal de Educação do Moju. Especialista em Metodologia do Ensino de Ciências Biológicas/UEPA.

2 Professora Universidade do Estado do Pará/UEPA. Possui mestrado pelo IEMCI. 
transporte, burocracia, falta de inclusão no currículo, dificuldades financeiras que impedem a utilização dos espaços não formais para a execução de aulas complementares sobre os temas que concernem a educação ambiental.

Palavras-chave: Dificuldades. Ambiental. Espaço não formal.

Abstract: This study aims to identify the main difficulties in performing activities identified in non formal about environmental issues, the teachers of the school city Moju. Data collection took place with visits and interviews with coordinators of non-formal settings: Park Radini present in the municipality of Abaetetuba-PA and Unity Screening and Recycling present in the municipality of Moju-PA. Semi-structured interviews were also conducted with teachers working at the school from 5 th to 8th grade Schools Antônio de Oliveira Gordo, Oton Gomes de Lima, Aunt Erica and Lauro Sodré present in the municipality of Moju-PA. Analyses were organized and discussed according to Discourse Analysis Orlandi (2001). According to the results, it was identified as major difficulties pointed out by the teacher's lack of time, lack of transportation, bureaucracy, lack of inclusion in the curriculum, financial difficulties that prevent the use of non-formal settings for running classes additional information regarding the issues concerning environmental education.

Keywords: Difficulties. Environmental. Non-formal space.

\section{Introdução}

Na Educação em Ciências, é possível identificar diversas tendências educacionais que permeiam os currículos escolares e trazem imbuídas em seu contexto histórico-social subsídios teóricos e metodológicos, a fim de suscitar adequações de conteúdos e métodos nas práticas realizadas por professores das ciências. Então, torna-se de grande importância a adoção das propostas metodológicas condizentes com as necessidades educacionais contemporâneas no ensino de Ciências,

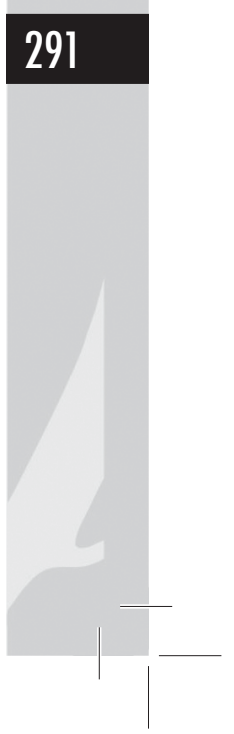




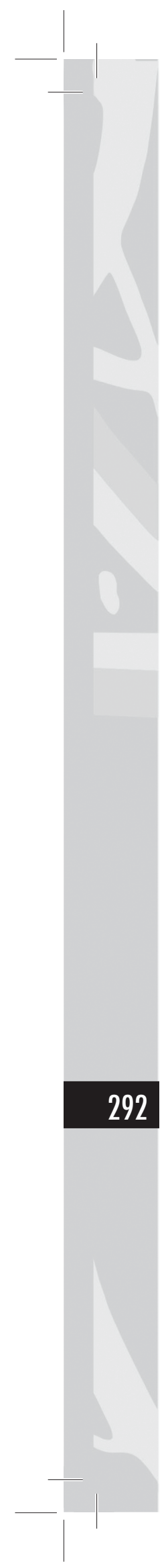

promovendo também a formação de alunos conscientes e participativos do processo democrático da sociedade.

A Educação Ambiental surge como tendência educacional a partir da década de 1960 e ganha maior destaque na década de 1970, com a realização de vários eventos e encontros que a afirmam como processo educacional. Pois, a partir do entendimento sobre as relações no e sobre o ambiente facilitam o aprendizado dos alunos, bem como a formação de sujeitos ativos e participativos em seu meio social, ambiental e cultural.

O desenvolvimento do processo de ensino e aprendizagem no Brasil sempre se desenvolveu em espaços educativos formais; porém, com o passar dos tempos às teorias, metodologias e práticas educativas trazidas pelas novas tendências, sugerem adequações no contexto educacional. E a Educação Ambiental assume uma nova postura, passando a acontecer em diversos espaços de ensino, considerados não formais, transpondo as barreiras limitadas da educação formal, com propostas educativas diferenciadas, com o intuito de acompanhar as demandas educacionais da atualidade.

Entre as novas metodologias empregadas, destacase o uso dos espaços não formais entre eles: museus, laboratórios, parques, unidades de reciclagem, jardins botânicos, zoológicos, e outros, como metodologias que têm um papel fundamental na complementaridade do ensino no processo de disseminação da educação, pois os mesmos suprem as necessidades como: a falta de laboratório que muitas escolas apresentam.

Motivados pela preocupação com a melhoria do ensino de ciência com enfoque ambiental em espaços não formais, procurou-se por meio desta pesquisa identificar quais as principais dificuldades que professores de Ciências da cidade de Moju-Pa, enfrentam na utilização de espaços não formais de ensino como o Parque Radini e a Unidade de Triagem e Reciclagem.

A problemática abordada surge da observação das práticas realizadas pelos docentes dessa região que se 
limitam na efetivação das atividades de ciências somente nos espaços da sala de aula, tendo na cidade de Moju espaços que são suporte didático e que poderiam ser utilizados para complementar as aulas de Ciências, bem como discutir relações do meio ambiente. Então, levantaramse as questões: Por que os professores se resumem em ensinar Ciências somente em sala de aula, tendo outros espaços para explorar os conceitos científicos? e Quais as principais dificuldades enfrentadas pelos professores no ensino fundamental a realizar atividades em espaços não formais em educação ambiental?

Este trabalho tem o objetivo identificar as principais dificuldades que levam os docentes do ensino fundamental da cidade de Moju ao realizarem atividades em espaços não formais em educação ambiental.

É importante fazer esse estudo para que se possa conhecer e entender os motivos pelos quais os espaços não formais são pouco ou não são utilizados para a promoção do Ensino de Ciências (EC) e poder intervir em tal situação. A busca de informações em fontes variadas é um procedimento importante para o ensino e aprendizagem de Ciências, em conformidade e a utilização de espaços não formais para a aquisição do ensino de ciência. Os espaços podem ser usados para complementar os saberes existentes na escola, pois nesses locais também se produz conhecimento por meio de observação, experimentação, leitura, entrevista e excursão ou estudo do meio (KRASILCHIK, 2008). Nesse sentido é importante que se tenha claro que a construção do conhecimento não se faz exclusivamente a partir de cada um desses procedimentos, e sim que todos estejam em conjunto.

\section{Referencial teórico}

Em meados da década 1970, surgiram os espaços não formais de ensino, que proporcionam uma educação igual ou até mais elaborada da que era oferecida nos espaços formais. O surgimento desses espaços de ensino ocorreu 


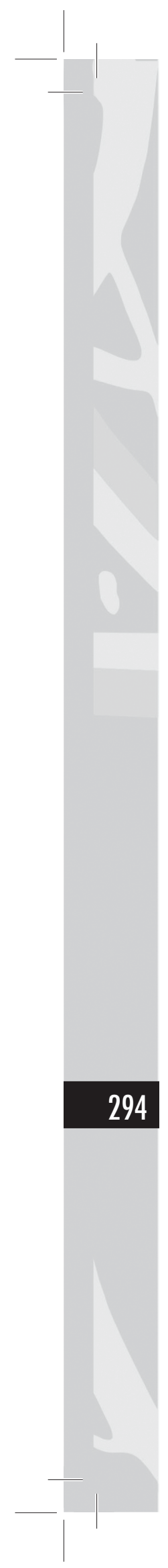

devido à organização de sindicatos e organizações não governamentais que passaram a lutar e discutir mecanismo que buscassem a melhoria da educação por meio da educação ambiental no Brasil.

Segundo Costa (2005), a educação não formal nos anos 1980 era vista como um conjunto de processos elaborados para alcançar o desenvolvimento de atividades educacionais voltada para a participação de indivíduos que moravam em áreas de extensão rural e desenvolviam atividades comunitárias. Carvalho (2006) concorda com a definição desses espaços que Costa faz, pois a mesma afirma que o desenvolvimento de práticas educativas não formais tende a envolver atuações em comunidades e assim são chamadas de EA (Educação Ambiental) comunitária ou, ainda, EA popular.

O que se percebe, é que a Educação não formal na década de 1980 era apenas utilizada para o ensino em comunidades do meio rural e só para que se tivesse uma educação básica. No entanto, alguns autores apontam que com o passar do tempo o significado de educação evoluiu, e Libâneo (1990) afirma que a educação não formal ocorre quando são desenvolvidas atividades educativas estruturadas fora do sistema escolar convencional como os parques ambientais, áreas de conservação, etc.

Bianconi et al. (2005) relatam que a educação nãoformal é definida como qualquer tentativa educacional organizada e sistemática que, normalmente, se realiza fora dos quadros do sistema formal de ensino. Já Vieira et al. (2005) definem que a educação não-formal é aquela que proporciona a aprendizagem de conteúdos da escolarização formal em espaços como museus, centros de ciências, ou qualquer outro meio em que as atividades sejam desenvolvidas de forma bem direcionada, com um objetivo definido.

E para Gohn (2008), a educação não formal para fins didáticos é dividida em dois tipos: $O$ primeiro destinase à alfabetização ou à transmissão de conhecimento que tem sido sintetizado na história por homens e mulheres, distintos das instituições escolares. No segundo, a educação ocorre no 
processo de participação social, que não são voltadas para se prender aos conteúdos da educação formal.

Percebe-se que, entre todos os autores, há uma concordância de que o ensino não formal ocorre em ambientes fora do contexto escolar, ou seja, fora da instituição educação formal. E também que é possível desenvolver o processo de ensino e aprendizagem nos espaços não formais como museus, centros de ciências, parques, unidade de conservação ou qualquer outro espaço em que as atividades sejam desenvolvidas de forma bem direcionada, com um objetivo definido.

Garcia (2003) argumenta que o surgimento da educação não formal não se dá com o objetivo de ocupar o espaço ou substituir o papel da educação formal [...], mas para dividir e partilhar os diferentes fazeres desse novo tempo. A utilização dos espaços não formais de ensino, quando aliados à educação formal criam mecanismos que ajudam no desenvolvimento do processo de ensino e aprendizagem, pois esses espaços de ensino não surgiram para substituir o espaço formal e, sim, para ajudá-lo a construir o processo de ensinoaprendizagem melhor.

A educação não formal sempre conviveu com a escolar. É provável imaginar sinergias pedagógicas muito produtivas entre as duas com interseções e complementariedade (PIVELLI, 2006).

Fica claro que, nos últimos anos, a educação não formal tem adquirido um maior desenvolvimento devido às práticas pedagógicas que vem desenvolvendo principalmente na área social, contemplando questão como cultura, saúde e meio ambiente (BARZANO, 2008).

Os espaços não formais de ensino se caracterizam com alguns princípios: 1) têm modo voluntário; 2) tendem a proporcionar a solidariedade e socialização; 3) buscar o desenvolvimento social, evitar formalidades e hierarquia; 4) busca a defesa da participação coletiva, proporcionando a investigação; 5) adequa a participação dos grupos de forma descentralizada (VON SIMSON, 2001). Isso demonstra que a educação não formal com seus princípios pode ajudar de

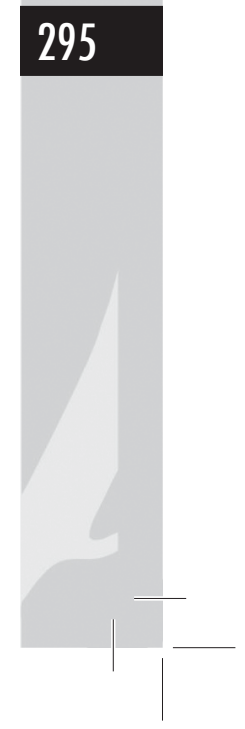


forma clara e eficaz, para melhorar o processo de ensino e aprendizagem em todos os níveis de ensino existentes.

A sociedade brasileira está em pleno desenvolvimento nas áreas de ciência, tecnologia, educação e meio ambiente. Por isso, é necessário que o conhecimento científicotecnológico seja de melhor qualidade, iniciando-se por meio da educação básica, envolvendo particularmente o ensino fundamental e médio, de modo especial através da formação de professores.

A educação em ciências utiliza métodos educacionais que vêm sendo cada vez mais desenvolvidos nos chamados espaços não formal de educação. Sabe-se que ensinar ciências é mais que fazer a fixação dos termos científicos que estão presentes em livros didáticos; deve-se também promover aos alunos situações de aprendizagem que possibilitem a formação de um arcabouço teórico the ajudando a desenvolver seu cognitivo. Porém, a construção dessas situações é uma tarefa árdua para os professores preocupados com o ensino. (BIANCONI et al., 2005)

Pesquisas realizadas junto ao público docente, realizada por M. Lucia Bianconi e Francisco Caruso (2005), apontaram que os espaços fora do ambiente escolar, mais habitualmente conhecidos como não formais, são compreendidos como recursos pedagógicos complementares às carências da escola, como, por exemplo, a falta de laboratório e a falta de contextualização dos livros didáticos que dificulta a possibilidade de ver, tocar e aprender fazendo.

A partir dos grandes eventos ocorridos nas décadas de 70 e 80 a respeito da temática ambiente, a educação ambiental vem sendo difundida como proposta educacional para formação de atitudes cidadã, podendo ser realizada em espaços formais $e$ não formais. A educação não formal é um processo de práticas educativas intencionalmente 
organizadas, geralmente dedicadas à população de todas as idades e que podem orientar-se em várias vertentes, para obtenção de conhecimentos ao desenvolvimento de valores e atitudes positivas face ao ambiente, incidindo, inclusive, por atividades de lazer. Os trabalhos nesta área podem ser mais ou menos estruturados, com propostas que trate de trilhas interpretativas, oficinas de reciclagem, hortas pedagógicas, cursos de formação e outros. (MENDONÇA, 2008)

Trilla (1996) afirma que a educação ambiental associa-se no processo educativo de todo cidadão e desenvolve-se respectivamente com outras atividades que se realizarão ao longo de sua vida. Esse fato faz com que a educação ambiental não formal tenha um papel fundamental na construção da cidadania.

O contexto social atualmente exige o empenho de todas as áreas do conhecimento para que possibilite criar subsídios que busquem medidas para ajudar a combater as degradações socioambientais. Nesse ambiente de crise, a educação e a ciência, principalmente a educação em ciência com enfoque na educação ambiental crítica, buscam contribuir cada vez mais na construção de um ambiente socioambiental menos degradado.

\section{METODOLOGIA}

Esta pesquisa apresenta parte da discussão desenvolvida no trabalho Educação Ambiental em espaços não formais: uma proposta para o ensino de Ciências, realizado para a conclusão do curso Licenciatura em Ciências Naturais com habilitação em Biologia da Universidade do Estado do Pará. Os sujeitos da pesquisa foram professores da rede municipal de Moju. O estudo consistiu em realizar uma pesquisa em espaços não formais para se saber com que frequência os professores da rede municipal de Moju utilização os referidos espaços nas suas aulas. 


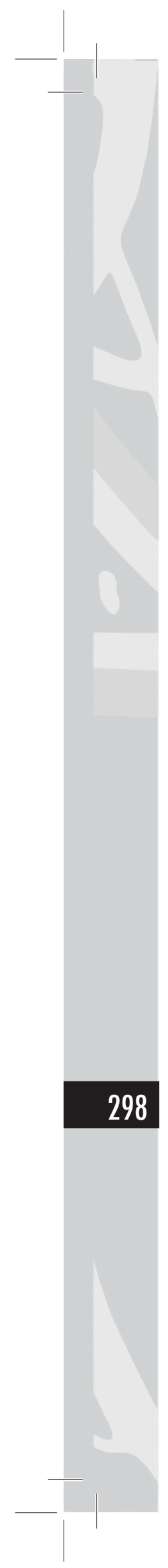

Os professores que participaram da pesquisa trabalham em três escolas: Lauro Sodré, Escolas Centro educacional Prefeito Oton Gomes de Lima e Tia Érica, todas localizadas no Município de Moju-Pa. Ao todo foram entrevistados seis educadores da disciplina Ciências do Ensino Fundamental maior de $5^{\mathrm{a}}$ a $8^{\mathrm{a}}$ serie.

Foi realizada entrevista semiestruturada com professores do Ensino Fundamental (EF) a fim de se investigar o que leva os professores a não utilizarem espaços considerados não formais como espaços pedagógicos para o desenvolvimento de atividades com foco à Educação Ambiental. A utilização de um roteiro pré-estabelecido não impediu a interação entrevistador-entrevistado, de modo a garantir certa flexibilidade para o entrevistador.

As entrevistas foram realizadas nas escolas onde os docentes trabalham, e a entrevista semiestruturada, realizada com os professores, consistiu em oito questões. As questões tiveram como objetivo coletar as narrativas dos professores, a fim de interpretar os motivos pelos quais os espaços de ensino não formal, Unidade de triagem e reciclagem e o parque Radini, eram pouco utilizados para a promoção do ensino de Ciências, visando práticas em Educação Ambiental.

Os espaços não formais que serviram de foco para a realização da pesquisa foram a Unidade de Triagem e Compostagem de Lixo, localizada na cidade do Moju na PA150, KM 4, e o Parque Radini localizado no estado do Pará, município de Abaetetuba. Nesses espaços, foram realizadas visitas, observações e entrevista com responsáveis, com o intuito de investigar se os espaços são utilizados como espaços favorecedores de ensino de Ciências para o desenvolvimento de práticas educativas sobre o tema Meio Ambiente.

Este artigo tem como objetivo apresentar as principais dificuldades apontadas pelos professores de Ciências em utilizar os espaços considerados não formais, mas que apresentam potenciais para a realização de atividades em Educação Ambiental. Este estudo se caracteriza como qualitativo, e tem como objetivo analisar os dados levantados pelas entrevistas, para pode apontar as principais dificuldades que os docentes 
encontram quando querem realizar aulas ou visitas no parque Radini e na unidade de triagem e reciclagem.

Segundo Ludke et al. (1986), o referencial qualitativo tem por característica a busca de significados e concepção explícitos ou implícitos na construção de dados a partir de descrições, tem caráter indutivo na análise dos dados e tem como fonte direta de investigação o próprio ambiente e a preocupação maior com o processo e com o produto. A pesquisa qualitativa não se preocupa com a enumeração ou medição dos eventos estudados, não se busca a generalização estatística dos dados e das constatações.

Neste artigo, apenas questões mais relevantes foram apresentadas. Para análise as respostas foram organizadas de acordo com as similaridades embasadas na Teoria da Análise do Discurso, segundo Orlandi (2001). Algumas questões foram tabuladas em forma de gráficos e tabelas, para melhor entendimento e discussão. Posteriormente, os resultados foram discutidos à luz dos referenciais teóricos pesquisados no trabalho.

\subsection{RESULTADOS E DISCUSSÕES}

\subsubsection{ANÁLISES DAS ENTREVISTAS COM OS COORDENADORES DOS ESPAÇOS NÃO FORMAIS}

No questionamento realizado com os coordenadores dos espaços não formais, objetivou-se identificar se existe algum tipo de aproximação ou trabalho com as escolas do município de Moju, a Unidade de Triagem e o Parque Radini.

Há alguns anos atrás existia uma relação, pois nós íamos às escolas administrar palestras, a campanha seletiva começou nas escolas distribuímos materiais ensinado o que é reciclável e o que não é reciclável, porém atualmente isso não ocorre. (Coordenação do URT)

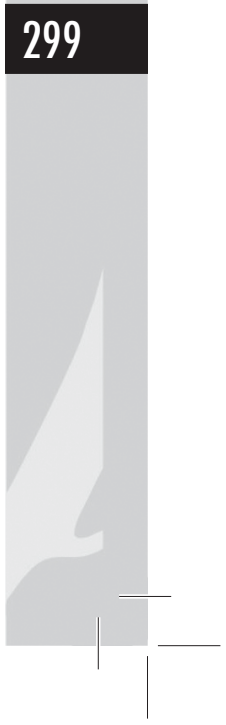


Existem relações com as escolas regiões próximas, Igarapé-Miri, Abaetetuba e a Universidade do estado do Pará de Moju, infelizmente com as escolas municipais de Moju não se tem nenhuma relação com $P R$. (Coordenação do PR)

Com os resultados observou-se que a UTR desenvolve atividades com as escolas de Moju, mesmo que esporadicamente, pois foi relatado pelo coordenador que algumas vezes receberam visitas dos alunos das escolas para realizarem palestras acerca de Meio Ambiente (MA), mas há algum tempo as atividades não ocorrem. O coordenador do Parque Radini informou que o fato de as escolas do município de Moju não manterem nenhuma relação com o Parque é muito negativo, pois com isso os alunos não têm possibilidades de adquirir conhecimentos fora do ambiente escolar, não sendo beneficiados com práticas mais dinâmicas, que envolvam atividades com enfoque ambiental, para que assim possam construir uma visão crítica e consciente, sobre o ambiente.

Segundo Brasil (1996), quando não existe uma relação entre as escolas e os espaços não formais, não se tem a aquisição de conhecimento por meios das atividades desenvolvidas. Assim, o que se prevê na Lei de Diretrizes e Bases da Educação Nacional (LDBEN) e seu artigo $3^{\circ}$, inciso $\mathrm{X}$, não se cumpre, pois essa Lei afirma que se deve levar em conta, no momento do ensino do educando no ambiente escolar, os conhecimentos obtidos em ambientes não formais de ensino.

2.1.2. ANÁLISES DAS ENTREVISTAS COM OS PROFESSORES

Uma das questões levantadas na pesquisa foi com relação à frequência em que ocorrem as visitas nos espaços não formais PR e da UTR. Nessa análise constatou-se que apenas um dos professores disse que utilizar os espaços não formais para promoção das suas aulas de ciências, e cinco professores informaram não utilizar outros espaços para a realização de atividades educativas. Essa análise não nos surpreendeu, visto 
que, pelo que se conhecia das entrevistas realizadas com os coordenadores dos espaços pesquisados, esses estabelecimentos têm sido pouco utilizados como espaços educativos pelos professores das escolas presentes na região.

Silva et al. (2007) afirmam que a utilização de espaços não formais como metodologia educacional possibilita integrar as diversas disciplinas acadêmicas num contexto diferente do ambiente escolar, pois permitem estabelecer uma conversa entre o que se está aprendendo na escola e a prática que pode ser aliada ao cotidiano dos alunos, contribuindo para diminuir a distância entre o pesquisador, a ciência, o desenvolvimento tecnológico e a vida das pessoas.

"Ao desenvolver o ensino de Ciências somente em ambiente escolar, a escola passa adquirir a postura autossuficiente do conhecimento de Ciências ou adquirir sua intencionalidade ou ignorância de resolução da perpetuação das deficiências no Ensino de Ciências" (PINTO et al., 2010).

Nesse contexto, os espaços não formais de ensino, como centros de Ciências, parque ecológicos, unidades de conservação, entre outros, podem auxiliar o ensino formal a favorecer a oportunidade maior de experimentação no conhecimento de Ciências. A experimentação tem papel importante no aprendizado de ensino de Ciências.

Outra questão que se buscou conhecer nos professores pesquisados foi a importância de se visitar outros espaços para promover aulas atrativas e compreensivas sobre ambiente. De acordo com os resultados, todos os professores consideram importante visitar outros espaços para promover aulas mais compreensivas sobre ciências e meio ambiente. Destacamos algumas respostas apresentadas pelos professores:

Com certeza tem a sua importância, porque tem aquele ditado que diz: ouço, entendo vejo aprendo, quando você leva o aluno para ele ter aquele contato direto e fizer a relação da pratica com a teoria é muito mais fácil para ele assimilar o conteúdo e tem mais interesse em aprender. (P1)

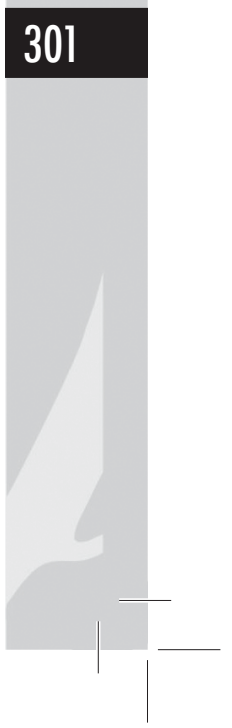


Considero importante porque, os espaços não formais às vezes conseguem contextualizar muito mais os conceitos que são aprendidos em sala de aula do que o próprio espaço escolar. (P2)

Lógico, é muito importante de todas as formas, tanto para os professores, quanto para os alunos. (P3)

Com esse resultado, foi possível perceber que os professores consideram importante a visitação de outros espaços para promover uma aula mais atrativa e contextualizada sobre ciências e meio ambiente, porém, apesar de considerarem importantes as visitações, eles não as praticam. É intrigante verificar que apesar de se saber da importância e das necessidades educacionais de utilizar outros espaços educativos, outras metodologias e formas diferenciadas de aprendizagem, ainda seja prevalente nas escolas práticas educativas tradicionais e ultrapassadas.

Segundo Krasilchik (2008), o uso dos espaços não formais de ensino constitui um método eficaz para o processo de ensino de ciências com enfoque ambiental, existem pesquisas que afirmam que a maioria dos professores de ciências considera muito importante a realização de atividades, porém, são poucos os docentes que realizam esse tipo de atividade.

Silva et al. (2007) concordam com que os professores disseram acima, pois afirma que os espaços não formais dão oportunidades aos alunos de interagirem, de verem, tocarem e aprenderem numa relação homem-natureza. Entende-se dessa forma que esses espaços de ensino oferecem subsídios para os professores de ciências emergindo como um desafio para tornar o ensino mais prazeroso, ampliando assim o interesse dos alunos. Solicitou-se aos professores, que informassem quais os motivos ou dificuldades enfrentadas para a utilização de espaços não formais na realização de suas aulas de ciências. Os resultados podem ser observados no Gráfico 1: 
Gráfico 1 - Principais dificuldades encontradas pelos docentes

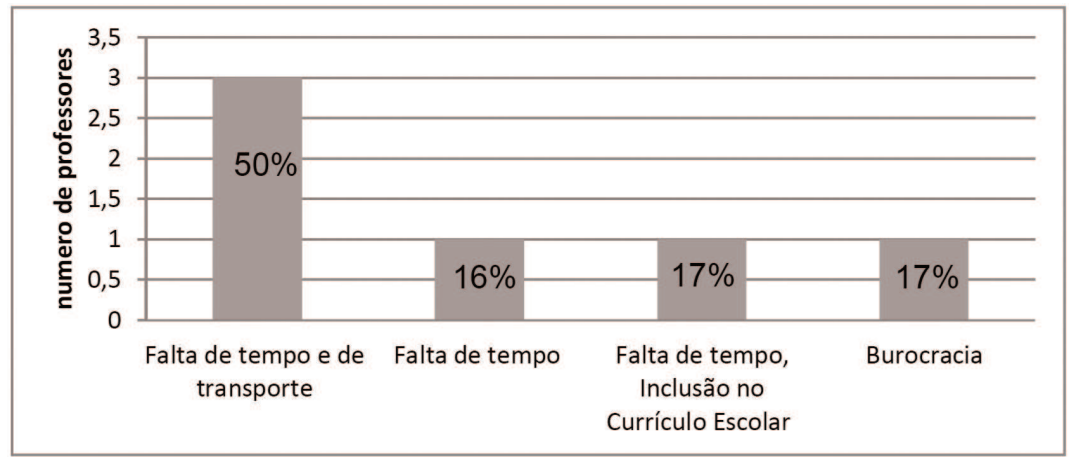

No gráfico pode-se destacar que três professores apontaram como principais dificuldades enfrentadas a falta de tempo e de transporte. De uma forma geral, quando se discute sobre a retirada dos alunos do espaço escolar, esses fatores são preponderantes e destacados pela maioria dos professores do nosso país, pois para ganhar um melhor salário os docentes têm uma carga horária excessiva de trabalho e geralmente não dispõem de transporte para realizar tais atividades o que os leva a sempre a desenvolver as atividades, prioritariamente, no espaço da escolar. No município de Moju, assim como em muitos municípios da nossa região, os poucos ônibus que há, geralmente, são utilizados para transportar alunos das áreas rurais para a cidade, onde se encontram as escolas formais, e esses transportes não podem ser usados para visitas, passeios ou outras atividades educacionais.

Apesar de haver tantas pesquisas e teorias em que se discute a questão da educação e do processo de ensino e aprendizagem, as nossas escolas ainda não contam com estruturas mínimas que proporcionem meios que facilitem aos educadores a realização de aulas diferenciadas. As escolas não têm um transporte para ser utilizado durantes atividades fora do espaço escolar, e sem falar da situação da nossa região, que sofre com o descaso de governantes, com instituições inadequadas, transportes insuficientes e precários e sem falar na falta de

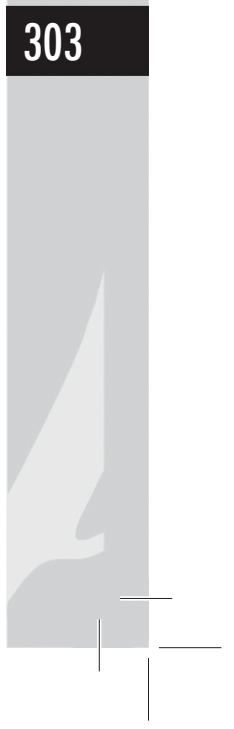


investimentos nos profissionais da educação. Com isso, as práticas em espaços não formais que auxiliariam no processo de ensino-aprendizagem não são realizadas.

Conforme Pinto et al. (2010) em pleno século XXI, a falta de transporte escolar, sugere muito mais de que uma falta de valorização dos espaços não formais de ensino do currículo escolar, do que simplesmente a falta de recurso financeiro. Esse fato sugere que o currículo de Ciências prejudicado, em sua prática, nesse aspecto, mais pelos órgãos governamentais em comparação ao corpo discente. Diante desse quadro, o estímulo dos professores é reduzido quando desejam ampliar o currículo do aluno além do universo escolar.

Um dos entrevistados disse que a principal dificuldade encontrada é a falta de tempo, pois muitos professores para terem um melhor salário trabalham no período da manhã, tarde e à noite em cerca de mais de dez turmas por dia. Apresentam-se alguns depoimentos dos professores que atestam isso.

E a questão do tempo, pois às vezes eu tenho cinco aulas com as turmas e para eu sair daqui com outra turma às outras turmas vão ficar sem professor e tem a questão da alimentação, e as dificuldades são muitas e não me deixa diversificar as aulas. (P.1)

Primeiro a gente encontra uma dificuldade como tempo, isso é um fator de dificuldade, uma vez que como a gente acaba tendo uma carga horaria excessiva isso faz com que a gente tenha pouco tempo para fazer um planejamento [...]. (P.2)

\section{[...] o tempo, que é muito restrito. (P.3)}

Segundo Praxedes (2010), os professores que trabalham com carga horária acima de 40 horas semanal tendem a não ter muito tempo para planejar uma aula mais dinâmica com seus alunos, muito menos uma aula num espaço não formal, e isso impossibilita qualquer iniciativa ou modificação na 
prática executada pelos professores prejudicando muito o desenvolvimento da aprendizagem dos alunos, pois as aulas somente de forma expositiva e tradicional desestimulam e não favorecem a aprendizagem que se deseja na atualidade.

Segundo Quadros (2011):

Esses professores demonstram entender que diversificar as aulas pode ser uma maneira de melhorar o ensino de Ciências e aumentar o engajamento dos estudantes. Mas, ao colocar isso como dificuldade, está assumindo que não tem os instrumentos necessários para fazê-lo ou não conhece suficientemente outras formas de ensino que o permitam diversificar. A interpretação dos dados nos mostrou que a maior parte dos professores coloca as dificuldades no trabalho centradas no "outro". Podemos inferir que, se as dificuldades em ensinar e aprender Ciências são externas a ele, não haverá preocupação em mudar sua prática e, por isso, provavelmente ficará aguardando melhorias que cheguem até ele, mas não o envolvam diretamente.

Um dos professores relatou que a dificuldade enfrentada é a falta de tempo com relação à questão da estrutura das escolas do conteúdo curricular, visto que, por não atender a uma única turma no horário em que estão na escola, deixarão de cumprir com o conteúdo durante a realização das atividades fora da escola. Ele afirma que vistas e atividades extracurriculares deveriam ser incluídas no planejamento de cada escola, pois só assim quando fossem fazer as visitas não deixariam outras turmas sem aulas. Apresentam-se abaixo os depoimentos do professor que atesta isso: "A principal dificuldade encontrada é que muitas vezes não há tempo para se realizar atividades nesses locais, as visitas deveriam ser incluídas no currículo da escola" (P.4).

Conforme Pinto et al. (2010) uma das características importante dos espaços não formais no currículo de Ciências é 


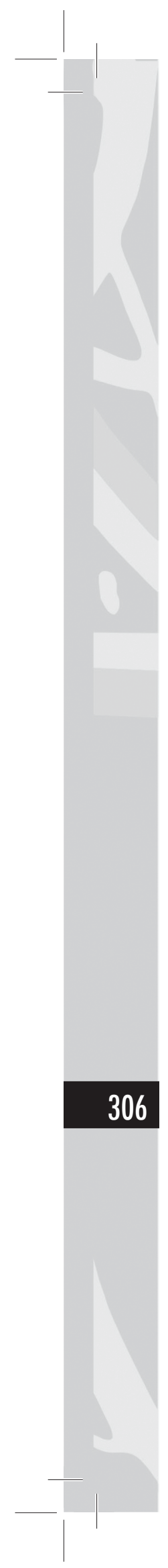

a chance de analisar os conteúdos de um modo desfragmentado, do que em um currículo baseado exclusivamente em diferentes áreas como Física, Química, Biologia e Matemática, dando um caráter mais multidisciplinar ao ensino.

O currículo escolar não pode ser apenas proposto e realizado no espaço escolar, mas elaborado também com objetivo de englobar locais nos quais os alunos possam ter uma reflexão mais ampla do conhecimento de Ciência que se tornará mais importante para o aprendizado. Os espaços não formais de ensino são locais onde não há a mesma intencionalidade e formalidade do espaço formal de ensino, por isso são, sem dúvida alguma, instrumentos importantes para efetivar a construção do conhecimento.

$\mathrm{Na}$ entrevista, um dos professores, informou que as principais dificuldades identificadas para a realização das visitas nos espaços não formais são relativas à questão da burocracia, a questão financeira e também à falta de tempo. Pois sempre que precisam fazer visitas eles precisam agendar ônibus com mais de um mês de antecedência, entrar em contato com as instituições, conseguir alimentação para os alunos levarem para se alimentarem. Isso muitas vezes não são conseguidos a tempo para que a visita ocorra, porque às vezes os espaços não formais agendam as vistas, mas os professores não conseguem o ônibus para levar os alunos.

Viera et al. (2007) apontam que em pesquisas realizadas com docentes sobre o uso dos espaços não formais as principais dificuldades apontadas e a falta de transporte e as despesas em geral.

Segundo Praxedes (2010, p. 71), o conteúdo relacionado às dificuldades apontadas citadas pelos professores foi reunido em quatro grupos:

1. Dificuldades de logística: esse tipo de dificuldade refere-se ao ato de planejar as visitas, de organizar, de locomoção ou transporte dos alunos, de parte da nutrição dos alunos e a estruturação para viabilização das visitas.

2. Dificuldades administrativas: são aquelas que se relacionam à burocracia, ao agendamento das visitas, à falta de tempo. 
3. Dificuldades pedagógicas: englobam obstáculos como a quantidade de alunos que podem visitar as instituições por vez, a falta de inclusão das visitas no currículo escolar, a falta de interdisciplinaridade entre as disciplinas.

4. Dificuldades financeiras: refere-se à condição financeira dos alunos e da escola.

As dificuldades para realização das aulas de Ciências decorrem da falta de estrutura e recursos, como foi citado, mas também devido à falta de preparação dos professores para o Ensino de Ciências. Esses apontaram ainda, a dificuldade de sair mais da escola para realizar aulas de campo em espaços não-formais, afirmando que falta apoio para dividir a responsabilidade de organizar, promover e realizar as saídas da escola.

\section{CONSIDERAÇÕES FINAIS}

No presente estudo, ficou explícito que os professores geralmente não utilizam os espaços não formais para realização das aulas de Ciências com enfoque na EA, cerca de $83 \%$ dos docentes disseram que não usam os espaços não formais para desenvolver suas aulas. No entanto, quando questionados se tivessem oportunidade de utilizar esses espaços em suas aulas, todos responderam que utilizariam.

Os docentes destacaram que existe uma grande vontade de realizar aulas mais dinâmicas, com a utilização da proposta feita neste trabalho. No entanto, para a realização de tais práticas, precisa-se de muito mais do que a boa vontade do professor.

Na pesquisa foi possível identificar algumas dificuldades que levam os docentes a não utilizarem esses espaços, tais como à falta de tempo, a falta de transporte, burocracia, falta de inclusão no currículo e dificuldades financeiras, constatou-se que o trabalho com espaços não formais, para se concretizar, requer um maior envolvimento da escola e dos governantes municipais. Pois, os espaços não formais de ensino que fizeram parte deste 


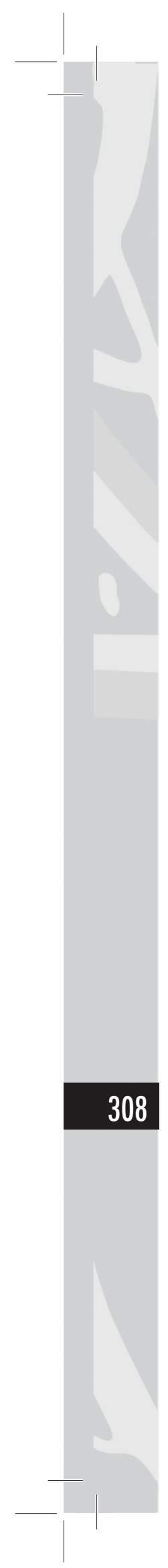

estudo têm um grande potencial para o desenvolvimento de atividades referentes à educação ambiental e estão abertos para receberem os alunos e os docentes para desenvolverem suas atividades, o que falta mesmo é um maior interesse em resolver as principais dificuldades que fazem com que esses espaços sejam poucos utilizados.

Construir práticas inovadoras para realização de atividades em educação ambiental significa contribuir para a construção de um campo teórico-metodológico necessário para o desenvolvimento e consolidação da educação ambiental como instrumento de produção, apropriação social e democrática dos conhecimentos na construção de uma sociedade mais justa e democrática.

Entende-se que esses achados são reflexo de uma prática educativa tradicional presa a um currículo educacional que não pode deixar de ser cumprido, e, de acordo com o percebido nesta pesquisa, retirar os educandos da sala de aula para fazer atividades em outros espaços necessitaria de muito tempo, disponibilidade do educador, dentre outros fatores, e comprometeria o conteúdo escolar.

Acredita-se que uma maneira de intervir na compreensão dos educadores a respeito da importância didática na utilização de espaços educacionais não formais para apropriação dos conteúdos científicos e leituras do mundo seria por meio de formações continuadas, com a compreensão de teorias e metodologia atuais que proporcionarão o entendimento de uma educação inovadora, rica em ambientes de aprendizado para as ciências naturais ou em qualquer área do conhecimento.

Espera-se com esse trabalho ter levantado discussões fecundas a respeito desta temática e que este sirva para suscitar outras inquietações e estudos visando contribuições nas práticas docentes, nos métodos educacionais, enfim no ensino de ciências. 
BARZANO, Marco Antônio Leandro. Educação não-formal: Apontamentos ao Ensino de Biologia. Departamento de Educação Universidade Estadual de Feira de Santana. [s.n] 2008.

BIANCONI, M. Lucia; CARUSO, Francisco. Apresentação educação não-formal. Ciência e Cultura, São Paulo, v. 57, n. 4, out./dez, 2005. BRASIL Lei de Diretrizes e Bases da Educação Nacional. Lei 9.394/96, de 20 de dezembro de 1996.

COSTA, Maria Angélica. A integralidade da educação ambiental e o ensino de ciências em espaços formais, informais e não-formais. Rio de janeiro. Instituto Oswaldo Cruz-IOC. [s. n] 2005.

GARCIA, V. A. R. e MARANINO, M. Levantamento preliminar dos programas de educação dos zoológicos brasileiros que utilizam material biológico em suas atividades. In: SELLES, Sandra E. et al. Anais do II Encontro Regional de Ensino de Biologia - Regional 02. São Gonçalo, 2003.

GOHN, Maria da gloria. Educação não-formal e cultura política. $4^{\circ}$ ed. São Paulo. Cortez, 2008.

KRASILCHIK, M. Práticas de Ensino de Biologia. São Paulo: Edusp. 2008.

LIBÂNEO, José Carlos. Didática. São Paulo: Cortez, 1990.

LUDKE, M; ANDRE M.E.D.A de. Pesquisa em educação: abordagens qualitativas. São Paulo: EPU, 1986.

MENDONÇA, Fabiana Ferreira; MACIEL, Claudia da Silva. Planejamento traçado para a implantação de uma Trilha de Interpretação natural na Estação Ecológica Radini, Abaetetuba- 
Pará. 2008. Trabalho de conclusão de Curso em Ciências Naturais com Habilitação em biologia. - da Universidade do Estado do Pará, Moju, 2008.

ORLANDI, Eni P. A linguagem e seus procedimentos: as formas do discurso. Campinas: Pontes Editores, 2001.276 p.

PINTO, Leandro Trindade; FIGUEIREDO Viviane Arena. O ensino de Ciências e os espaços não formais de ensino: Um estudo sobre o ensino de Ciências no município de Duque de Caxias/RJ. [n. 179] Programa de Pós-graduação em Ensino de Ciências e Tecnologia. Universidade Tecnológica Federal do Paraná - UTFPR. 2010.

PIVELLI, Sandra Regina Pardini. O potencial pedagógico de espaços não formais de ensino para o desenvolvimento da temática da biodiversidade e sua conservação. 2006. Dissertação de Mestrado. Faculdade de Educação de São Paulo, São Paulo, 2006.

PRAXEDES, Gutemberg de Castro. Utilização de espaços de educação não formal por professores de Biologia da cidade de Natal - RN. 2009. Dissertação de Mestrado. Universidade Federal do Rio Grande do Norte, Centro de Ciências Exatas e da Terra, Natal, 2009.

QUADROS, Ana Luiza de et al. Ensinar e aprender Química: a percepção dos professores do Ensino Médio. Educ. rev., n. 40, Curitiba, abr./jun. 2011. Disponível em: http://dx.doi.org/10.1590/ S0104-40602011000200011. Acesso em: 4 mar. 2012.

SILVA, Viviane Aparecida. A relação entre a Educação Ambiental Formal: um estudo de caso do Parque Natural Municipal de Taquara e as escolas do entorno. 2007. Trabalho de Conclusão de Curso. Faculdade de Educação da Baixada Fluminense, Rio de Janeiro, 2007.

TRILLA, J. La Educación Fuera de la Escuela - Ámbitos no formales de educación social. Barcelona: Ariel, 1996. 
VIEIRA, Valéria; BIACONI, Maria Lucia. A importância do museu Nacional da Universidade Federal do Rio de Janeiro para o ensino não formal em ciência. Ciências e Cognição 2007, ano IV. V.11. Disponível em: http://www.cienciascogniçao.org./artigos/ v11/337166.html. Acesso em: 13 set. 2011.

VIEIRA, Valéria; BIANCONI M. Lucia; DIAS, Monique. Espaços não formais de ensino e o currículo de ciências. Ciência Cultura, v. 57, n. 4, São Paulo, out./dez. 2005.

VON SIMSON, Olga R. M.; PARK, Margareth B.; FERNANDES, Renata S. (orgs). Educação não-formal: cenários da criação. Campinas: Editora da UNICAMP/ Centro de memória, 2001.

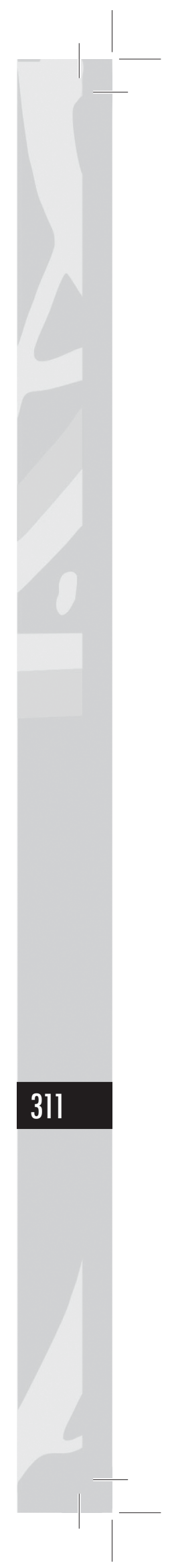

